\title{
CIMTEC 2006 to Be Held in Sicily in June \\ www.cimtec-congress.org
}

The 11th International Conference on Modern Materials and Technologies (CIMTEC 2006) will be held in Acireale, Sicily, June 4-9, 2006. Chaired by P. Vincenzini (World Academy of Ceramics) and co-chaired by R.J. Nemanich (International Union of Materials Research Societies, USA) and R. Freer (International Ceramic Federation, U.K.), the conference will feature the 11th International Ceramics Congress, dealing primarily with ceramics, and the 4 th Forum on New Materials, which involves a diverse spectrum of advanced inorganic and organic materials.

The 11 general sections of the Ceramic Congress will encompass all major aspects of current ceramics research, including fundamentals of structure, property, reaction, and unit processes; corrosion and tribology; powders synthesis and processing; sintering science and technology; nonconventional routes; surface engineering; ceramic composites; joining; structural ceramics; ceramics for electrochemical, chemical, energy, environmental, and refractory applications; and electric, magnetic, and optical ceramics.

The Forum on New Materials encompasses five international conferences: the 3rd International Conference on Mass and Charge Transport in Inorganic Materials; the 5th International Conference on Science and Engineering of Novel Superconductors; the 4th International Conference on Diamond and Other New Carbon Materials; the 7th International Conference on Materials in Clinical Applications; and the 5th International Conference on Advanced Inorganic Fibrous Composites for Structural Applications; as well as three special symposia, Disclosing Materials at Nanoscale, Spin Injection and Transport in Magnetoelectronics, and Biomedical Applications of Nanotechnologies.

The more than 400 confirmed invited speakers at the various sections, conferences, and symposia will address the latest advances and emerging research fields. Emphasis will be placed on the most relevant directions for materials research based on new theory and refined modeling strategies and on the increasing opportunities offered by the progress made in nanoscience and nanotechnology.

Main endorsing organizations of CIMTEC 2006 are the International Union of Materials Research Societies (IUMRS), the World Academy of Ceramics (WAC), and the International Ceramic Federation (ICF). The first announcement and call for papers may be downloaded from the conference Web site at www.cimtec-congress. org, which also contains all relevant information about abstract submission and participation. Abstract deadline is October 15, 2005.

For further information, contact CIMTEC 2006, PO Box 174, 48018 Faenza, Italy; tel. +0546-22461, fax +0546-664138, and e-mail: congress@technagroup.it.

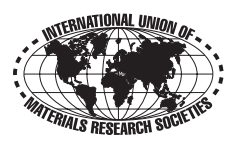

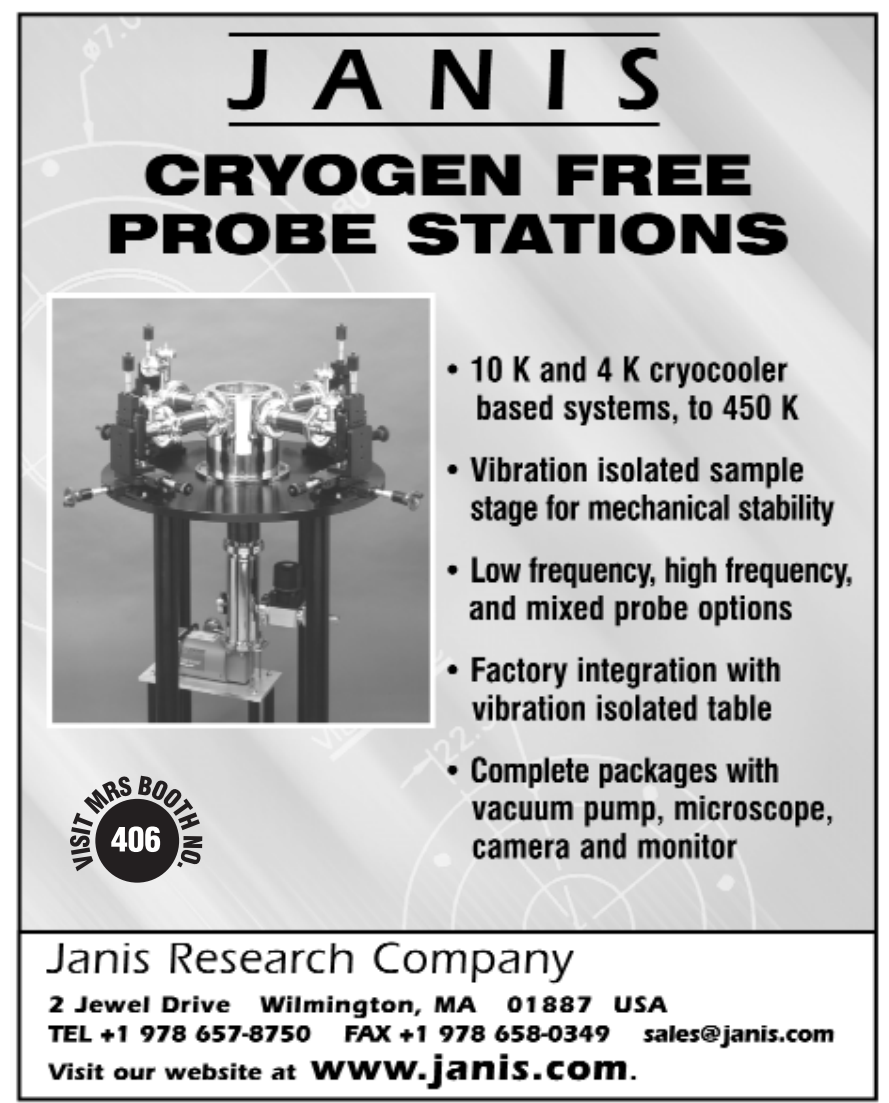

For more information, see http://advertisers.mrs.org

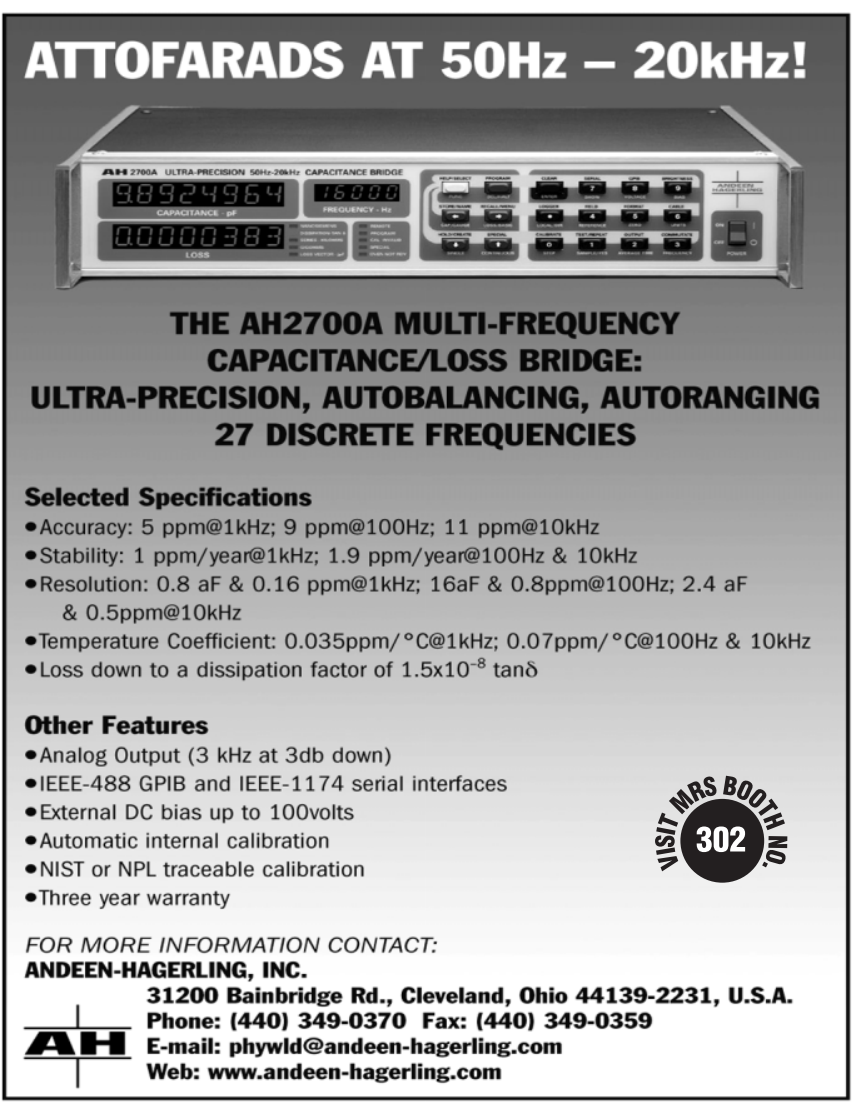

For more information, see http://advertisers.mrs.org 